\title{
BMJ Open Effect of body mass index on vertebral and hip fractures in older people and differences according to sex: a retrospective Japanese cohort study
}

\author{
Kyohei Shiomoto (D) , ${ }^{1,2}$ Akira Babazono, ${ }^{3}$ Yumi Harano, ${ }^{3,4}$ Takako Fujita (D) ,3,5 \\ Peng Jiang, ${ }^{3}$ Sung-A Kim (D) , ${ }^{3}$ Yasuharu Nakashima ${ }^{2}$
}

To cite: Shiomoto K, Babazono A, Harano $\mathrm{Y}$, et al. Effect of body mass index on vertebral and hip fractures in older people and differences according to sex: a retrospective Japanese cohort study. BMJ Open 2021;11:e049157. doi:10.1136/ bmjopen-2021-049157

- Prepublication history and additional supplemental material for this paper are available online. To view these files, please visit the journal online (http://dx.doi.org/10.1136/ bmjopen-2021-049157).

Received 20 January 2021 Accepted 12 October 2021

Deck for updates

(c) Author(s) (or their employer(s)) 2021. Re-use permitted under CC BY-NC. No commercial re-use. See rights and permissions. Published by BMJ.

For numbered affiliations see end of article.

\section{Correspondence to}

Dr Kyohei Shiomoto;

k-shio@ortho.med.kyushu-u. ac.jp

\section{ABSTRACT}

Objectives The purpose of this study was to investigate the incidence of vertebral and hip fractures in the older people and to clarify the relationship between these fractures and body mass index (BMI) along with the impact of sex differences.

Design

This was a retrospective cohort study.

Setting

We used administrative claims data between April 2010 and March 2018.

Participants Older people aged $\geq 75$ years who underwent health examinations in 2010 and were living in the Fukuoka Prefecture, Japan were included in the study. A total of 24691 participants were included; the mean age was $79.4 \pm 4.3$ years, 10853 males and 13838 females, and an the mean duration of observation was $6.9 \pm 1.6$ years.

Primary and secondary outcome measures We estimated the incidence of vertebral and hip fractures by BMI category (underweight: $<18.5 \mathrm{~kg} / \mathrm{m}^{2}$, normal weight: $18.5-24.9 \mathrm{~kg} / \mathrm{m}^{2}$, overweight and obese: $\geq 25.0 \mathrm{~kg} / \mathrm{m}^{2}$ ) using a Kaplan-Meier curve in males and females and determined fracture risk by sex using Cox proportional hazards regression analyses.

Results The incidence of vertebral and hip fractures was $16.8 \%$ and $6.5 \%$, respectively. The cumulative incidence of vertebral and hip fracture at the last observation (8 years) in each BMI groups (underweight/normal weight/ overweight and obese) estimated using the KaplanMeier curve was $14.7 \% / 10.4 \% / 9.0 \%$ in males and $24.9 \% / 23.0 \% / 21.9 \%$ in females, and $6.3 \% / 2.9 \% / 2.4 \%$ in males and $14.1 \% / 9.0 \% / 8.1 \%$ in females, respectively, and both fractures were significantly higher in underweight groups regardless of sex. Multivariable Cox proportional hazards models showed that underweight was a significant risk factor only in males for vertebral fractures and in both males and females for hip fractures.

Conclusion Underweight was associated with fractures in the ageing population, but there was a sex difference in the effect for vertebral fractures.

\section{INTRODUCTION}

Vertebral and hip fractures are the major fractures that occur in the older people. The
Strengths and limitations of this study

- This was a retrospective cohort study including 24691 older peoples.

- We followed up participants for approximately 7 years.

- We investigated the incidence of vertebral fractures and hip fractures in the older people and evaluated the relationship between body mass index (BMI) and fractures and differences by sex.

- We evaluated the relationship between BMI and fracture by adjusting for major factors such as age, smoking and osteoporosis, as well as comorbidity using the Charlson Comorbidity Index.

- This study has several limitations; bone mineral density, a factor closely related to fracture, could not be assessed in this study, and although we assessed osteoporosis comorbidity, we could not assess treatment status.

incidence of these fragility fractures appears to be increasing in many countries because of the increasing size of populations. ${ }^{1-3}$ Gullberg et al reported that the incidence of hip fractures in the world was estimated to nearly double, from 2.6 million hip fractures in 2025 to 4.5 million in 2050 , with a particularly marked increase in Asia. ${ }^{2}$ Both vertebral and hip fractures cause pain and dysfunction and decrease quality of life (QOL). ${ }^{4-6}$ It is well known that there is a high mortality rate after hip fracture, but there are also reports of increased mortality after vertebral fractures. ${ }^{78}$ Consequently, among fragility fractures, vertebral and hip fractures greatly impact healthy life expectancy and longevity. In Japan, where the ageing population is rapidly increasing, the economic burden of these fractures is immeasurable and has become an important public health issue. ${ }^{910}$ Therefore, in order to prevent these fractures in the older people, it is very important to understand what are the risk factors. 
Previous studies reported several risk factors for vertebral and hip fractures, with the most important risk being age, sex, history of past fractures and low bone mineral density (BMD). ${ }^{11} 12$ The fracture risk assessment tool (FRAX), which is known as a fracture prediction tool, also uses these factors, smoking and alcohol consumption as fracture risks. ${ }^{13}$ The prevalence of osteoporosis is also high in the elderly, and the coexistence of osteoporosis has a significant impact on fractures. ${ }^{14}$ Body mass index (BMI) is another well-documented risk factor that it is closely related to fragility fractures. ${ }^{15-17}$ Underweight has been recognised as a risk factor for vertebral and hip fractures, and a cohort study in Japan reported underweight as a preventable risk factor for hip fracture. ${ }^{18} \mathrm{On}$ the other hand, Johansson $e t a l^{16}$ reported that the association between BMI and fracture risk is complex and differs across skeletal sites; thus, the relationship between BMI and fracture risk is still controversial. Previous study has shown that the effect of BMI on hip fracture varies with age. ${ }^{19}$ Sex and race may also influence the relationship between BMI and fractures. Although BMD varies by race, there was a report that even after excluding the effects of BMD, there was a difference in fracture risk by race. ${ }^{2021}$ Some studies reported that the impact of BMI on fractures varies by $\operatorname{sex}^{1622}$; however, there is no consensus regarding this, especially in Japanese.

In this study, using the healthcare claims database of the Fukuoka Prefecture, the following questions were addressed: (1) What is the incidence of vertebral and hip fractures in the older people who live in Fukuoka Prefecture? (2) Is there a relationship between BMI and fracture risk and is there a difference between males and females?

\section{MATERIALS AND METHODS}

\section{Study design and data source}

We used data from the healthcare claims database and master database of the Fukuoka Prefecture Wide-Area Association of Latter-stage Elderly Healthcare between 1 April 2010 and 31 March 2018. This public health insurance is open to people over the age of 75 years and those aged 65-74 years with disabilities, and the majority of people over the age of 75 years have this insurance. The total population of Fukuoka Prefecture is about 5.1 million, the ninth largest in Japan, and about 520000 older people are covered by this insurance. Most of the insured have long-term eligibility once they are enrolled; therefore, few participants were lost to follow-up except for death. The databases included data for the International Classification of Diseases 10th Revision (ICD-10) codes; date of diagnosis, medical procedures, such as surgery, date of admission and death. The database are mostly computer administered. According to a report by the Japanese Ministry of Health, Labour and Welfare, the penetration rate of computer-administered claims databases was $98.6 \%$ as of April 2015. ${ }^{23}$ Older people aged 75 and over who are enrolled in this health insurance and who do not have regular hospital visits for lifestyle-related diseases are eligible for medical examination. We also used data from the 2010 health examination, which included participants' height, weight, BMI, smoking and use of alcohol.

\section{Participants}

Our target population was people who held Fukuoka Prefecture Wide-Area Association of Latter-stage Elderly Healthcare insurance and who met the following criteria: (1) People who underwent the 2010 health examination; (2) age $\geq 75$ years at the health examination; (3) data related to smoking and alcohol consumption at the time of health examination were available and (4) no history of vertebral or hip fracture before the health examination. Fracture history was investigated using self-reports at the time of the health examination and the medical claims database to determine if there were any fractures prior to the health examination.

\section{Follow-up duration}

The follow-up duration was defined as from the date of the participant's 2010 health examination to the date of death or until March 2018. There was a slight discrepancy because participants did not have a consistent date for their health examination.

\section{Outcomes (vertebral and hip fracture incidence)}

We identified patients with vertebral (ICD-10 code $=$ S22.0 -1 , S32) and hip (ICD-10 code=S72.0-2) fractures diagnosed between the date of the medical examination and 31 March 2018 in the medical database and investigated the cumulative fracture incidence. We also investigated the time to each primary fracture. A second fracture at the same site was not included. Participants who died during the follow-up period were also included as fracture patients if they had a fracture before death.

\section{Comparison by BMI category}

The BMI classification in the general WHO is widely used in Japan, and we used the following cut points. Participants were divided into three groups according to BMI category as follows: underweight $\left(<18.5 \mathrm{~kg} / \mathrm{m}^{2}\right)$, normal weight $\left(18.5-24.9 \mathrm{~kg} / \mathrm{m}^{2}\right)$ and overweight and obese $\left(\geq 25.0 \mathrm{~kg} / \mathrm{m}^{2}\right)$. Participants' demographics and the incidence of vertebral and hip fractures were compared between the BMI categories.

\section{Risk factors for vertebral and hip fractures}

We examined age, BMI, use of alcohol, smoking, comorbidities and osteoporosis as risk factors for each fracture by sex. BMI was divided into three categories as described above, and the fracture risk of 'underweight' and 'overweight and obese' was examined using normal as the reference. Age was categorised into three groups: $75-79$ years, $80-84$ years and $\geq 85$ years. Smoking and use of alcohol were divided into two groups, habitual and non-habitual, and were used as separate risk factors. The Charlson Comorbidity Index (CCI) was used as an indicator of each participant's comorbidities. ${ }^{24} \mathrm{CCI}$ was calculated at 
the health examination using the ICD-10 $\operatorname{codes}^{25}$ and was divided into four groups: low (0), medium (1-2), high (3-4) and very high $(\geq 5)$. Osteoporosis was identified using the ICD-10 codes (M80, M81, M82). Incidentally, the diagnostic criteria for osteoporosis in Japan are (1) BMD value less than $70 \%$ of Young adult mean (YAM), (2) history of vertebral fracture or proximal femur fracture or (3) history of fragility fracture other than vertebral fracture or proximal femur fracture at less than $80 \%$ of YAM.

\section{Participant and public involvement}

We used administrative claims data and did not involve participants in this study.

\section{Statistical analysis}

Statistical analyses were performed using Stata software, V.14 (StataCorp). All continuous variables were examined for normality with the Shapiro-Wilk test. Since all continuous variables were non-normal, the Wilcoxon signed-rank test was used for two-group comparisons and the Steel-Dwass test was used for three-group comparisons. For qualitative variables, the $\chi^{2}$ test was used. We estimated the incidence proportion of vertebral and hip fractures by BMI category using a Kaplan-Meier curve in males and females, and differences between groups were tested for statistical significance using the log-rank test in males and females. To examine the risk factors for vertebral and hip fracture by sex, Cox proportional hazards regression analyses were performed using the following factors: age, BMI, use of alcohol, smoking, osteoporosis and CCI. All risk factors were used as categorical variables. Statistical significance was set as $\mathrm{p}<0.05$. Continuous values were expressed as mean $\pm \mathrm{SD}$.

\section{RESULTS \\ Participants}

Of the people who held Fukuoka Prefecture Wide-Area Association of Latter-stage Elderly Healthcare insurance, 26005 underwent the 2010 health examination. We excluded 1314 people: 691 people were younger than 75 years at the time of the health examination, 109 people had missing data related to their drinking and smoking, and 514 people had a history of fracture; therefore, 24691 participants were included in this study. Participants' demographic data are shown in table 1. The mean observation period was 6.9 years, and 5409 people died during this period. There was a significantly higher proportion of older age and underweight groups in females compared with males $(p<0.0001)$. Males had significantly higher CCI, smoking, and use of alcohol than females $(p<0.0001)$. The prevalence of osteoporosis

Table 1 Patient's demographic data

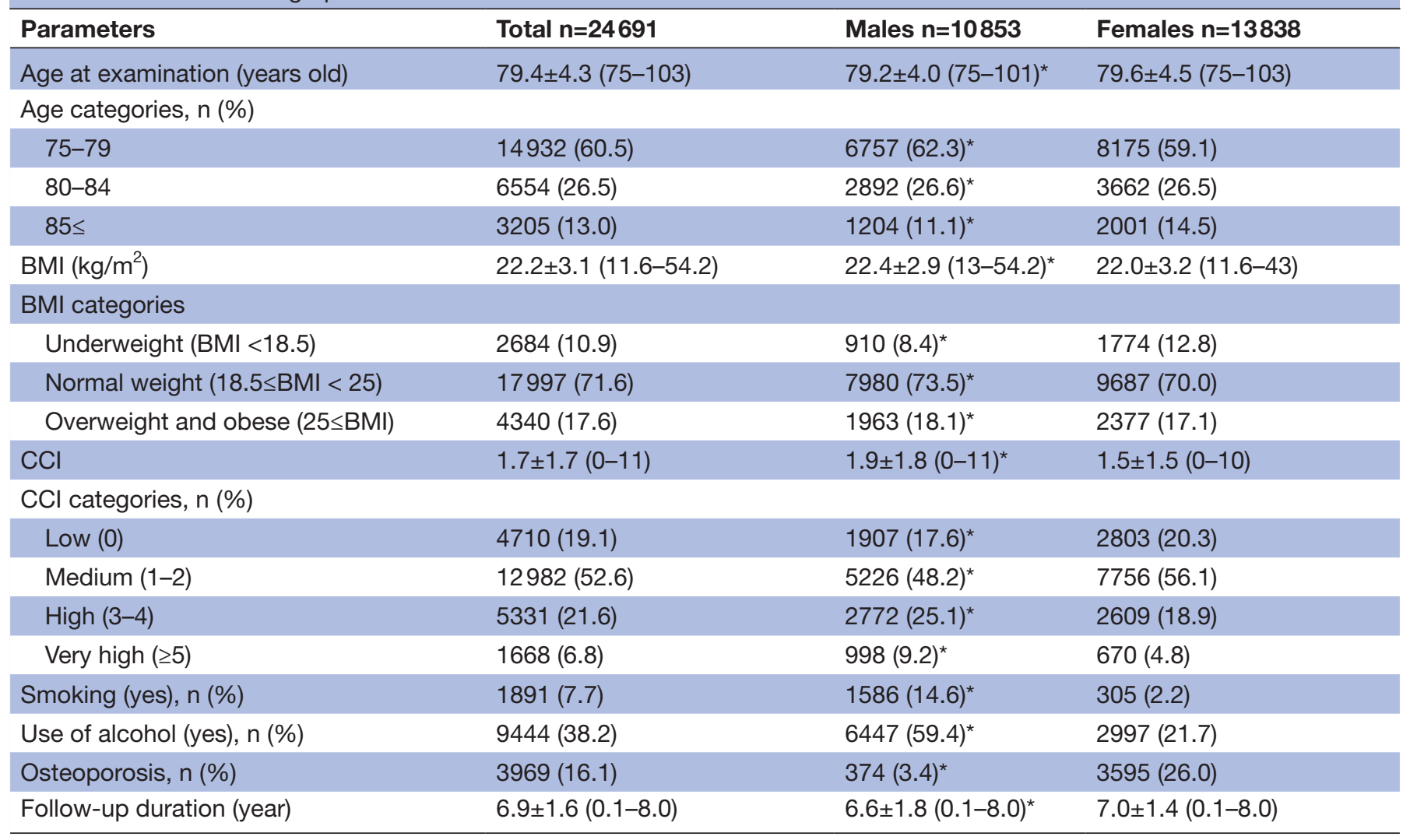

Continuous values are expressed as mean \pm standard deviation (range).

*Significantly different between males and females $(p<0.05)$.

$\mathrm{BMI}$, body mass index; $\mathrm{CCl}$, Charlson Comorbidity Index. 
Table 2 Comparison of participants' demographics between BMI categories

\begin{tabular}{|c|c|c|c|}
\hline \multirow[b]{2}{*}{ Parameters } & \multicolumn{3}{|l|}{ BMI categories } \\
\hline & $\begin{array}{l}\text { Underweight } \\
n=2684\end{array}$ & $\begin{array}{l}\text { Normal weight } \\
n=17667\end{array}$ & $\begin{array}{l}\text { Overweight and obese } \\
n=4340\end{array}$ \\
\hline Age at examination (years old) & $80.8 \pm 4.8(75-103)^{*} \dagger$ & $79.4 \pm 4.2(75-103) \ddagger$ & $78.9 \pm 4.0(75-99)$ \\
\hline \multicolumn{4}{|l|}{ Age categories, n (\%) } \\
\hline $75-79 / 80-84 / 85$ & $\begin{array}{l}1291(48.1) / 828(30.8) / \\
565(21.1)^{+\dagger}\end{array}$ & $\begin{array}{l}10775(60.9) / 4691(26.6) / \\
2201(12.5) \ddagger\end{array}$ & $\begin{array}{l}2866(66.1) / 1035(23.8) / \\
439(10.1)\end{array}$ \\
\hline Sex; males/females, n (\%) & $910(33.9) / 1774(66.1)^{*} \dagger$ & 7980 (45.2)/9687 (54.8) & $1963(45.2) / 2377(54.8)$ \\
\hline $\mathrm{BMI}\left(\mathrm{kg} / \mathrm{m}^{2}\right)$ & $17.2 \pm 1.0(11.6-18.4)^{*} \dagger$ & $21.8 \pm 1.7(18.5-24.9) \ddagger$ & $26.9 \pm 1.9(25-54.2)$ \\
\hline $\mathrm{CCl}$ & $1.6 \pm 1.6(0-10) \dagger$ & $1.7 \pm 1.7(0-11) \ddagger$ & $1.9 \pm 1.8(0-10)$ \\
\hline \multicolumn{4}{|l|}{$\mathrm{CCl}$ categories, $\mathrm{n}(\%)$} \\
\hline $\begin{array}{l}\text { Low }(=0) / \text { medium }(=1-2) / \\
\text { High }(=3-4) / \text { very high }(\geq 5)\end{array}$ & $\begin{array}{l}481(17.9) / 1426(53.1) / \\
574(21.4) / 203(7.6) \dagger\end{array}$ & $\begin{array}{l}3425(19.4) / 9.349(52.9) / \\
3759(21.3) / 1134(6.4) \ddagger\end{array}$ & $\begin{array}{l}804(18.5) / 2207(50.9) / \\
998(23.0) / 331(7.6)\end{array}$ \\
\hline Smoking (yes), n (\%) & $266(9.9)^{*} \dagger$ & $1346(7.6) \ddagger$ & $279(6.4)$ \\
\hline Use of alcohol (yes), n (\%) & $786(29.3)^{*} \dagger$ & 6939 (39.3) & 1719 (39.6) \\
\hline Osteoporosis, n (\%) & $537(20)^{*} \dagger$ & 2806 (15.9) & $626(14.4)$ \\
\hline Follow-up duration (year) & $6.4 \pm 2.0(0.1-8.0)^{\star} \dagger$ & $6.9 \pm 1.5(0.1-8.0) \ddagger$ & $7.1 \pm 1.3(0.1-8.0)$ \\
\hline
\end{tabular}

Continuous values are expressed as mean \pm SD (range).

${ }^{*} \mathrm{P}<0.05$ for significantly different between underweight and normal weight.

$\dagger P<0.05$ for significantly different between underweight and overweight and obese.

$\ddagger \mathrm{P}<0.05$ for significantly different between normal weight and overweight and obese.

$\mathrm{BMI}$, body mass index; $\mathrm{CCl}$, Charlson Comorbidity Index.

was significantly higher in females $(\mathrm{p}<0.0001)$. Online supplemental appendix 1 shows the prevalence of the comorbidities used to calculate the CCIs.

\section{Comparison of patients lost to follow-up due to death versus those that remained alive}

Those that died during follow-up were older, more male, had lower BMI, higher CCI and more smokers than those that survived (all $\mathrm{p}<0.0001)$. Details are shown in online supplemental appendix 1 .

\section{Vertebral and hip fracture rate}

Vertebral and hip fractures occurred in 4153 (16.8\%) and $1543(6.5 \%)$ of the participants, respectively, during the study period. Vertebral fractures occurred in $1082(10 \%)$ males and $3071(22.2 \%)$ females, hip fractures occurred in $314(2.9 \%)$ males and $1229(8.9 \%)$ females, and the incidence of both fractures was significantly higher in females $(p<0.0001)$. The incidence of vertebral fracture was 150 in males and 315.9 in females per 10000 personyears, respectively. The incidence of hip fracture was 43.5 in males and 126.4 in females per 10000 person-years, respectively. A total of 520 participants had both vertebral and hip fractures, with a significantly higher number of females $(\mathrm{p}<0.0001)$.

\section{Comparison by BMI category}

A comparison of participants' demographics by BMI category is shown in table 2. Underweight group was present in a significantly higher proportion of people aged $\geq 85$ years, in females, and in those who smoked, than in the other two BMI groups $(\mathrm{p}<0.0001)$. There was a significantly lower proportion of use of alcohol with underweight group $(\mathrm{p}<0.0001)$. Overweight and obese group was associated with a significantly higher CCI than the other two BMI groups $(\mathrm{p}<0.01)$.

The cumulative incidence of vertebral and hip fracture in each BMI groups (underweight/normal weight/ overweight and obese) at the final follow-up estimated using the Kaplan-Meier curve was 21.5\%/17.3\%/16.1\% and $11.4 \% / 6.2 \% / 5.5 \%$, respectively (all p $<0.0001$ ) (figure 1). By sex, the cumulative incidence of vertebral fracture in each BMI groups was $14.7 \% / 10.4 \% / 9.0 \%$ in males and $24.9 \% / 23.0 \% / 21.9 \%$ in females, respectively, and was significantly higher with underweight group in both sexes $($ all $\mathrm{p}<0.05)$ (figure 2$)$. Similarly, the cumulative incidence of hip fracture was $6.3 \% / 2.9 \% / 2.4 \%$ in males and $14.1 \% / 9.0 \% / 8.1 \%$ in females, respectively, and was significantly higher with underweight group in both sexes (all $\mathrm{p}<0.0001$ ) (figure 3 ).

\section{Risk factors of vertebral and hip fractures}

In univariate analysis, the HRs $(95 \% \mathrm{CI})$ for age, BMI, alcohol, smoking, CCI and osteoporosis for the vertebral fracture were $2.4(2.0-2.8) / 1.5 \quad(1.3-1.8) / 1.0$ $(0.9-1.1) / 0.9(0.8-1.1) / 2.8(2.2-3.6) / 2.2(1.8-2.8)$ in males, and $1.3(1.2-1.5) / 1.1(1.0-1.2) / 0.9(0.9-1.0) / 1.1$ $(0.9-1.4) / 2.0(1.7-2.4) / 1.5(1.4-1.6)$ in females, respectively. The HRs (95\% CI) for age, BMI, alcohol, smoking, CCI, and osteoporosis for the hip fracture were 3.9 $(2.9-5.2) / 2.2(1.7-3.0) / 0.7(0.6-0.9) / 1.4(1.0-1.8) / 3.8$ 

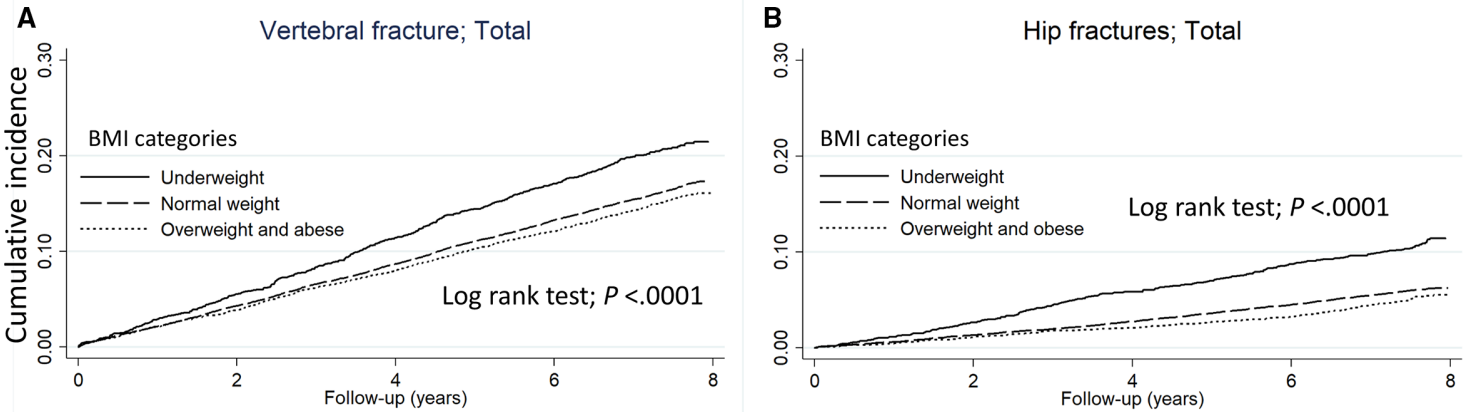

Figure 1 The Kaplan-Meier curve shows the incidence of $(A)$ vertebral fractures and (B) hip fracture compared by BMI category. The solid line represents underweight, the dashed line represents normal weight, and the dotted line represents overweight and obese. BMI, body mass index.

(2.3-6.3)/1.6 (1.0-2.7) in males and $4.0(3.5-4.6) / 1.6$ $(1.4-1.8) / 0.8(0.7-0.9) / 1.1 \quad(0.7-1.6) / 3.4(2.6-4.4) / 1.3$ $(1.2-1.5)$ in females, respectively. Older age, underweight, higher CCI and osteoporosis were significant risk factors for vertebral fracture in both males and females (table 3). Multivariable analysis showed that older age, higher CCI and osteoporosis were risk factors for vertebral fracture in both males and females, but underweight was a significant risk factor only in males (table 3).

In multivariable analysis, the adjusted HRs for age, BMI, alcohol, smoking, CCI and osteoporosis for the vertebral fracture were $2.1(1.8-2.5) / 1.3(1.1-1.6) / 1.1(0.9-$ 1.2)/0.9 (0.8-1.1)/2.5 (2.0-3.3)/1.8 (1.4-2.3) in males, and $1.2(1.1-1.4) / 1.1(1.0-1.2) / 1.0(0.9-1.1) / 1.2(0.9-$ $1.5) / 1.8(1.5-2.1) / 1.4(1.3-1.5)$ in females, respectively. The adjusted HRs for age, BMI, alcohol, smoking, CCI and osteoporosis for the hip fracture were $3.2(2.4-4.3) / 1.7$ $(1.3-2.4) / 0.8(0.6-1.1) / 1.4(1.0-1.8) / 3.3(2.0-5.5) / 1.2$ $(0.7-2.0)$ in males, and $3.7(3.2-4.2) / 1.4(1.2-1.6) / 0.9$ $(0.8-1.1) / 1.1(0.8-1.6) / 2.7(2.1-3.5) / 1.1(1.0-1.3)$ in females, respectively. Older age, higher CCI and osteoporosis were significant risk factors for hip fracture in both males and females, and smoking was also a significant risk factor in males (table 4). Multivariable analysis showed that older age and higher CCI were significant risk factors for hip fracture in both males and females, smoking was a significant risk factor only in males, and osteoporosis was a significant risk factor only in females (table 4). Use of alcohol had a significant protective effect on hip fractures in males.

\section{DISCUSSION}

In this study, we evaluated the cumulative incidence of vertebral and hip fractures in the older people over an average of 6.9 years using the healthcare claims database in the Fukuoka Prefecture. Older people holding the Fukuoka Prefecture Wide-Area Association of Latterstage Elderly Healthcare insurance rarely drop out of the programme, and the health insurance covers most older people aged $\geq 75$ years who live in this area. Therefore, the strength of this study is that there were almost no drop-outs other than because of death, and that we were able to investigate the occurrence of fractures regardless of the medical institution where the diagnosis was made. Previous studies reported that the incidence of vertebral fracture at age $\geq 60$ years was $13 \%-18 \% .^{26-28}$ Tamaki et al found in a 3-year retrospective cohort study that the incidence of hip fracture in people aged 80-84 years was 36.6 and 88 per 10,0000 , for males and females, respectively. ${ }^{29}$ We found that the incidence of vertebral and hip fracture was $17 \%$ (150 and 316.4 per 10,000, for males and females) and 7\% (43.5 and 126.4 per 10000 , for males and females), respectively, in our study. The incidence rates in this study were equivalent to those in previous
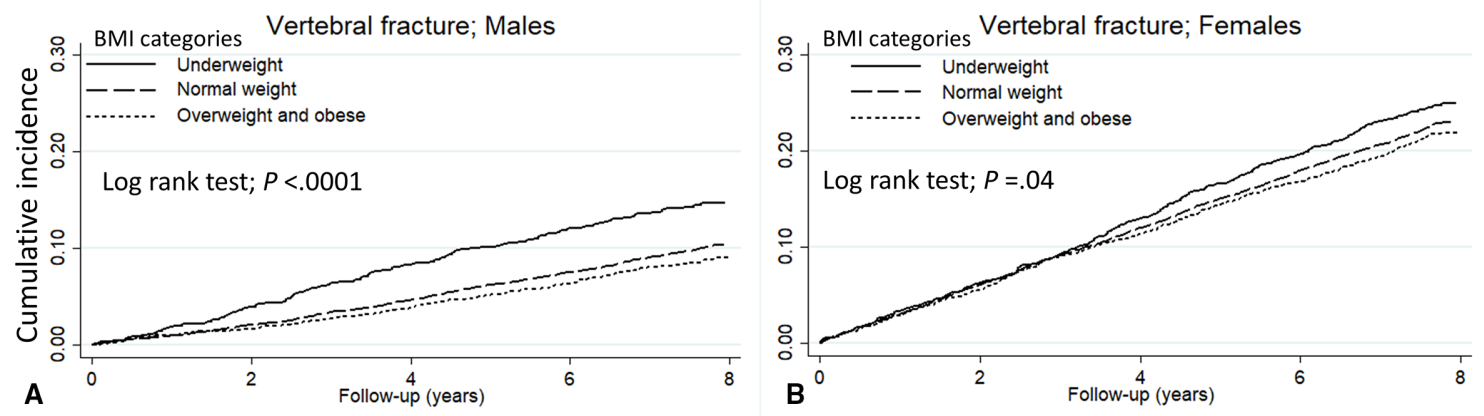

Figure 2 The Kaplan-Meier curve shows the incidence of vertebral fractures in (A) males and (B) females compared by BMI category. The solid line represents underweight, the dashed line represents normal weight, and the dotted line represents overweight and obese. BMI, body mass index. 

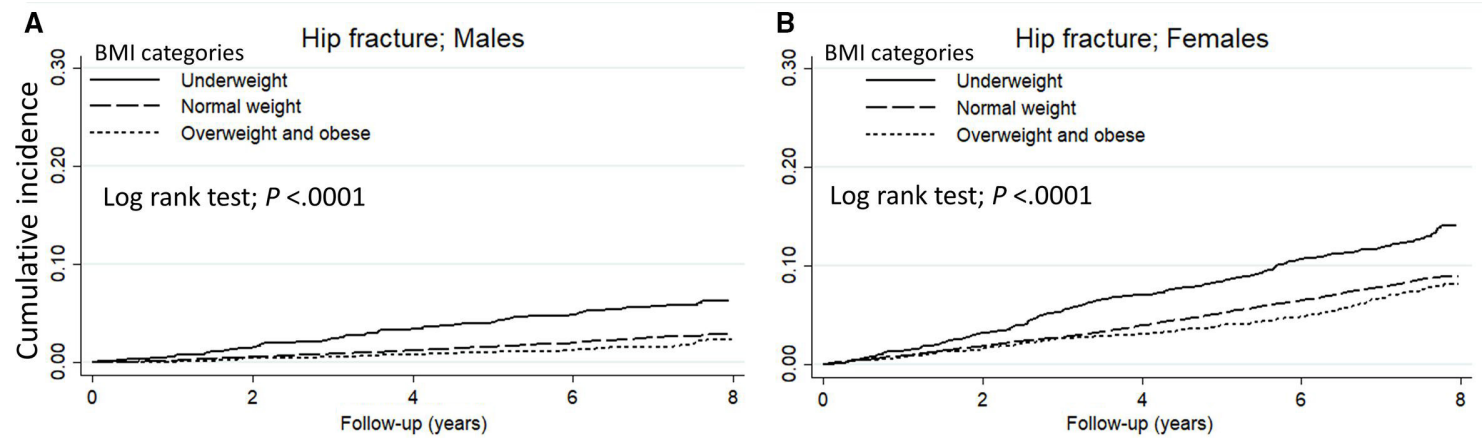

Figure 3 The Kaplan-Meier curve shows the incidence of hip fracture in (A) males and (B) females compared by BMl category. The solid line represents underweight, the dashed line represents normal weight, and the dotted line represents overweight and obese. BMI, body mass index.

cohort studies and did not appear to be unevenly distributed by region. ${ }^{26-29}$

Using this large cohort data, our study demonstrated that the vertebral and hip fracture incidence was higher in the underweight group (BMI $<18.5 \mathrm{~kg} / \mathrm{m}^{2}$ ) according to the Kaplan-Meier curve. As many previous studies reported, underweight has long been considered an important risk factor for fractures. Generally, lower BMI is associated with lower BMD, and Lloyd et al reported that every unit increase in BMI is associated with an increase of $0.0082 \mathrm{~g} / \mathrm{cm}$ in BMD30. ${ }^{30}$ De Laet $e t a l^{5}$ also reported that low BMI was a significant risk factor for fracture, even after adjusting for BMD, and that low BMI was associated with an increased relative risk, especially for hip fracture. In this study, underweight was also associated with higher HR for hip fracture than vertebral fracture, suggesting that underweight may have a particular impact on hip fracture among fragility fractures. Although underweight is generally considered a risk factor for fragility fractures, several reports have shown that the relationship between BMI and fracture risk may differ by sex and skeletal site, and that the relationship is complex. ${ }^{15}{ }^{16}$ In the current study, we investigated the effect of BMI on fractures, stratified by sex. We found that underweight was a risk factor for hip fractures regardless of sex, and for vertebral fractures, underweight was a risk factor only in males. Kaze $e t$ $a l^{17}$ reported in their meta-analysis that an inverse association between BMI and risk for vertebral fracture in present in males but not in females. Several previous studies have shown that underweight is consistently associated with the risk of hip fracture, regardless of sex. ${ }^{1631}$ Johansson et $a l^{16}$ found that the relationship between BMI and osteoporotic fractures depended on the site of the fracture, although their study was conducted only on females. In this study, we similarly suggested that the effect of BMI varied by fracture site in females. Several reports have indicated that abdominal fat may affect bone independently of total body fat, and that there are sex differences in fat

Table 3 Cox proportional hazards analysis of the risk factors for vertebral fracture

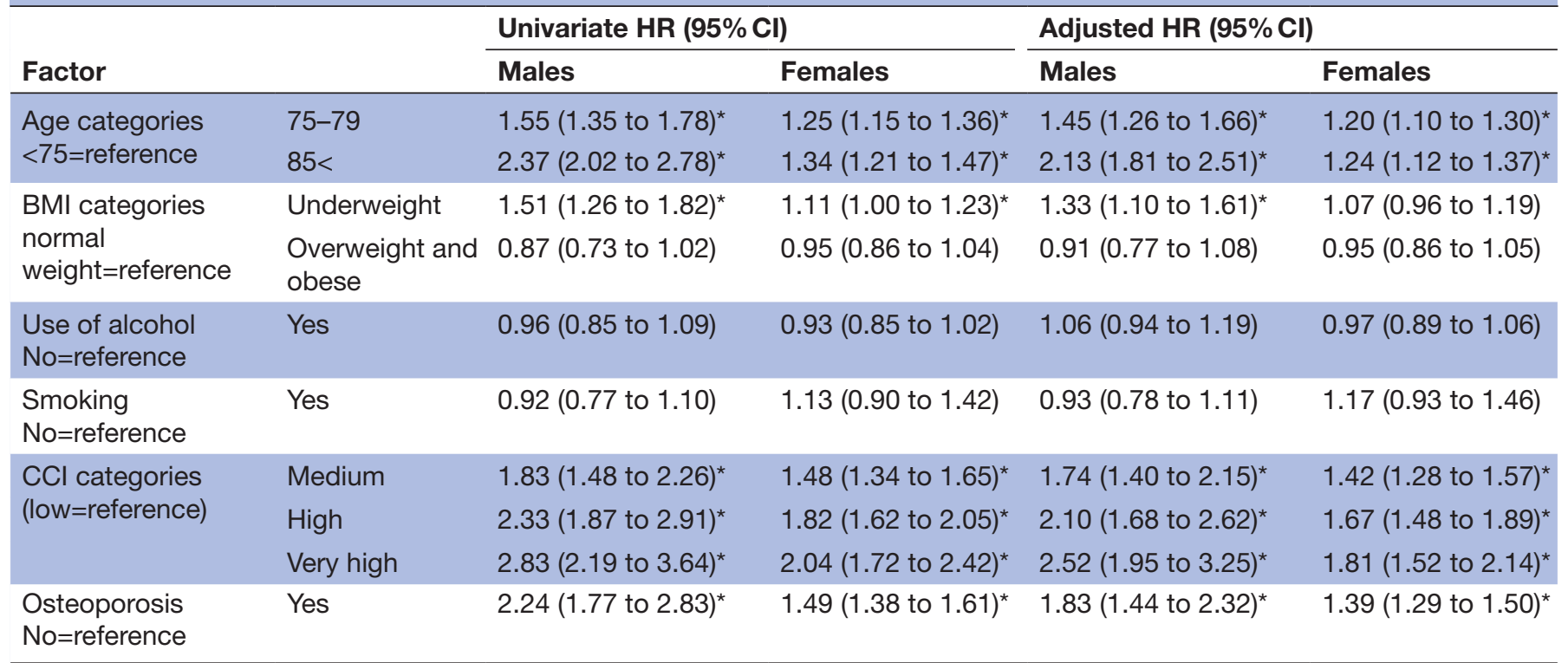

Age, BMI, use of alcohol, smoking, $\mathrm{CCl}$ and osteoporosis were used as covariates.

*Statistically significant difference compared with reference $(p<0.05)$.

$\mathrm{BMI}$, body mass index; $\mathrm{CCl}$, Charlson Comorbidity Index. 
Table 4 Cox proportional hazards analysis of the risk factors for hip fracture

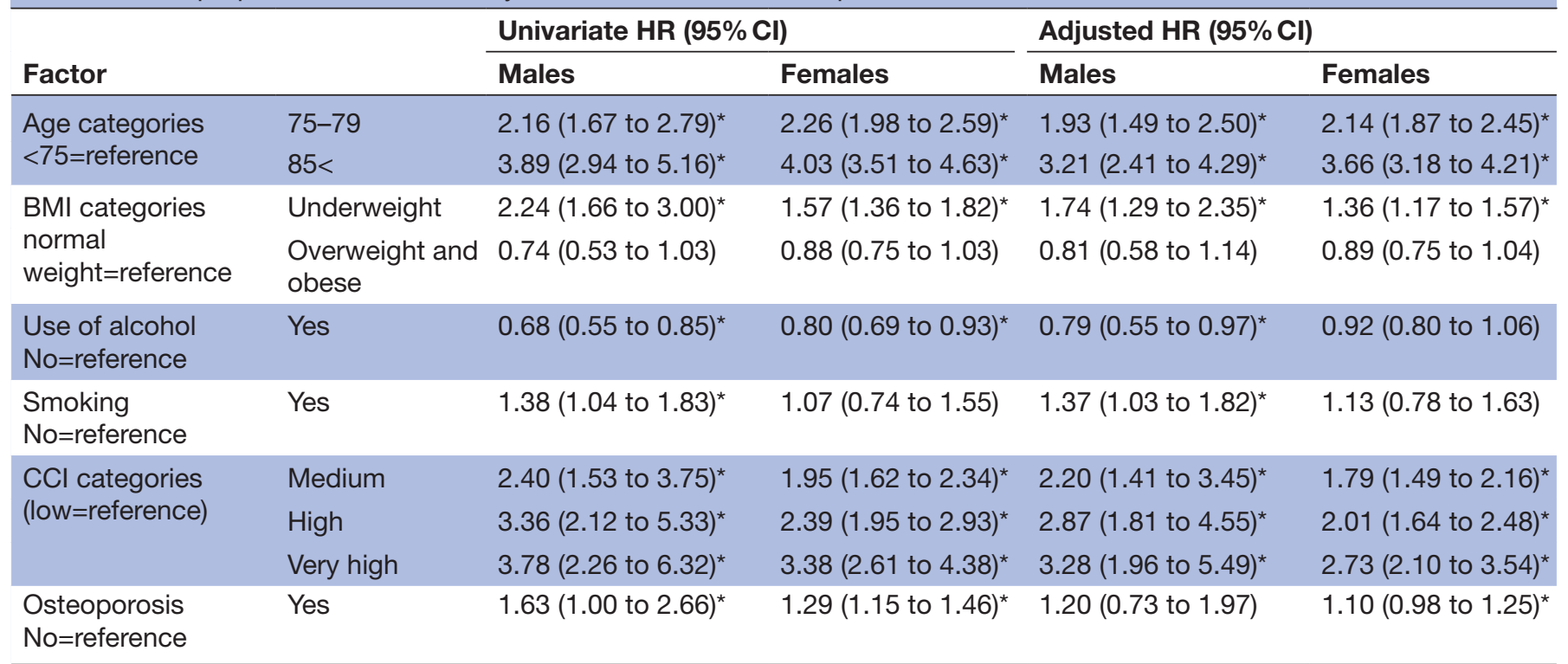

Age, BMI, use of alcohol, smoking, $\mathrm{CCl}$ and osteoporosis were used as covariates.

*Statistically significant difference compared with reference $(p<0.05)$.

$\mathrm{BMI}$, body mass index; $\mathrm{CCl}$, Charlson Comorbidity Index.

distribution, which may be a possible reason for the sex differences in the effect of BMI on fracture. ${ }^{32} 33$ However, the reasons for the site-specific sex effects, as shown in this study, are not yet well understood. Another possible explanation could be that BMI as a measure of adiposity has been shown to be less valid in the older people owing to age-related changes in body composition. ${ }^{34}$ However, in this study, only the older people were included, not the middle-aged or other groups of both males and females, and this effect is considered to be small.

Not only is low BMI considered a risk factor for fracture, but a preventive effect of high BMI on fracture has recently been discussed. Some reports suggest that obesity has a protective effect on fractures because of higher BMD and reduced impact of falls as a result of increased soft-tissue padding. ${ }^{35} 36$ However, it has not been proven that obesity is protective against all fractures, and the relationship between obesity and fracture has been reported to be fracture site-specific. ${ }^{37} 38$ Although there are some reports of sex differences in the preventive effect of BMI on fractures, ${ }^{31} 39$ the results are mixed and the preventive effect of BMI on fractures is still unclear. We found that obesity had no protective effect on vertebral and hip fractures, regardless of sex, even after adjusting for confounding factors such as age and comorbidity. Therefore, the effect of obesity on fracture prevention may be poor in the ageing Asian population.

Further research is still needed to determine whether high BMI has a protective effect on fractures in the ageing population. However, underweight in the older people is consistently associated with a higher risk of fracture, which can have a greatly impact QOL in the future. BMI can be easily measured at a health examination, and screening for fracture risk according to BMI is effective in terms of healthcare costs for the healthy life span of the older people. Prolonged healthy life expectancy of the older people is associated with; the additional assessment of exercise function, further assessment of fracture risk by measuring BMD, and fracture prevention in the older people with underweight at the health examinations.

Using the Cox proportional hazards model, we found other factors besides BMI that influenced vertebral and hip fractures. The comparison of HRs suggested that age and CCI may have a greater effect on fracture than BMI. First, for both types of fractures, older age and higher CCI increased the risk of fracture. Although it is a well-known finding that the incidence of fragility fractures increases with age, the effect of ageing was more prevalent in hip fractures. Tamaki et $a l^{29}$ reported a marked increase in fracture risk after the age of 80 , indicating that the very older people are at extremely high risk of fracture. This may be related to the decline in physical function and increased risk of falling with age. Comorbidities such as chronic kidney disease, diabetes and dementia are associated with increased risk of fragility fractures, and it is useful to evaluate the presence of comorbidities and investigate their contribution to the risk of fractures. ${ }^{40-42}$ CCI was originally used to assess the risk of comorbidities for death, but patients at high risk of death with a high CCI may also be at higher risk of fragility fractures. This study stratified CCI and assessed the risk of fracture and showed that a higher CCI was associated with a higher fracture risk. Therefore, CCI may be useful in assessing fracture risk as well as mortality risk in the older people.

Second, health-related behaviours such as smoking and use of alcohol are also well-established risk factors 
for fragility fractures, ${ }^{43} 44$ in this study, smoking was a risk factor in hip fractures in men. Iconaru et al reported that smoking was a significant risk factor for only hip fractures among fragility fractures, ${ }^{45}$ and the effect of smoking on fracture may also be site-specific. The lack of effect of smoking in females may be related to the extremely low rate of smoking ( $15 \%$ in males and $2 \%$ in females) in older females. The results of this study showed that use of alcohol had a protective effect on hip fractures in males. Several reports state that light to moderate alcohol consumption decrease age-related bone loss, and that heavy alcohol consumption is associated with elevated hip fracture risk, while light alcohol consumption is inversely related to fracture risk. ${ }^{44}{ }^{46}$ We did not assess the amount of alcohol consumed in this study and therefore are unable to discuss the effect of alcohol consumption on fracture risk.

Finally, the coexistence of osteoporosis is an important factor in osteoporotic fractures. The results of this study showed that osteoporosis affected vertebral fractures in both males and females, but only hip fractures in females. One reason for this may be the difference in the pathogenesis of osteoporosis, in which females, unlike males, experience two phases of bone loss: menopausal bone loss and age-related bone loss. Another possible explanation is that the prevalence of osteoporosis at the time of physical examination was quite low in the males in this study.

This study has several limitations. First, we used a retrospective design and data from a claims database and medical examination, which did not include BMD values. Therefore, it is not possible to say whether BMI is a risk factor for fractures independent of BMD. However, this does not change the fact that BMI is a simpler and more useful tool for fracture evaluation. Second, the claims and medical examination data used in this study were derived from public insurance covering people aged $\geq 75$ years, and the results may differ for younger populations, such as those in middle age. However, the fracture prevalence increases sharply in those over 70 years of age, ${ }^{29}$ and we believe that the evaluation used in this study is useful in other vulnerable population. One of the strengths of our study was that the follow-up rate for people aged $\geq 75$ years who were covered by the insurance was extremely high. Third, since the fracture occurrence was extracted from the medical claims data using ICD-10 codes, asymptomatic vertebral fractures could not be extracted, and there is a concern that the number of vertebral fractures may have been underestimated. In addition, we were not able to obtain detailed information on the actual occurrence, for example, whether it was a fall or a traffic accident. Fragility fractures, which are the main focus of this study, are commonly caused by low-energy trauma. Therefore, the limitation is that some fractures from high energy trauma may be included in the study. Forth, this study referred to osteoporosis using ICD-10 codes, but failed to mention drug treatment. The coexistence of osteoporosis influences the occurrence of fractures, but the effect may vary greatly depending on the type of drug, the duration of medication, and other circumstances of osteoporosis treatment. This study was not able to investigate osteoporosis treatment and could not address the effect of osteoporosis treatment. Finally, this study was performed exclusively in Japan, where ethnic diversity is limited. Compared with the Japanese, Western populations have a relatively high BMI, and our findings may not be generalisable to other populations.

\section{CONCLUSION}

The incidence of both fractures was higher in the underweight population. After adjustment for possible confounders, underweight was a risk factor for vertebral fracture only in males, and there were sex differences in the effect of BMI. Underweight was a risk factor for hip fracture in both males and females, and underweight is likely to remain important in the ageing population. Evaluating older people with underweight at health examinations and providing therapeutic interventions may help prevent subsequent fractures and improve healthy life expectancy.

\section{Author affiliations}

${ }^{1}$ Artificial Joints and Biomaterials, Faculty of Medical Science, Kyushu University, Fukuoka, Japan

${ }^{2}$ Orthopaedic Surgery, Kyushu University Faculty of Medicine Graduate School of Medical Science, Fukuoka, Japan

${ }^{3}$ Health Care Administration and Management, Kyushu University Faculty of Medicine Graduate School of Medical Science, Fukuoka, Japan

${ }^{4}$ Saga-Ken Medical Center Koseikan, Saga, Japan

${ }^{5}$ Department of Health Sciences, Faculty of Medical Sciences, Kyushu University, Fukuoka, Japan

Acknowledgements The authors would like to thank the Fukuoka Prefecture Wide-Area Association of Latter-Stage Elderly Healthcare for allowing access to the health claims database and master data.

Contributors KS led the study design, extracted and analysed the data, conducted the literature search, and wrote the manuscript. $A B$ and $Y N$ contributed to the study design, analysis and manuscript revision. YH, TF, PJ and S-AK contributed to data analysis and reviewed the manuscript. All authors read and approved the final version of the manuscript. KS is the paper's guarantor.

Funding The authors have not declared a specific grant for this research from any funding agency in the public, commercial or not-for-profit sectors.

Competing interests None declared.

Patient consent for publication Not applicable.

Ethics approval This study was approved by the Kyushu University Institutional Review Board for Clinical Research (Approval No. 20209).

Provenance and peer review Not commissioned; externally peer reviewed.

Data availability statement No data are available. Data sharing statementNo additional data are available.

Supplemental material This content has been supplied by the author(s). It has not been vetted by BMJ Publishing Group Limited (BMJ) and may not have been peer-reviewed. Any opinions or recommendations discussed are solely those of the author(s) and are not endorsed by BMJ. BMJ disclaims all liability and responsibility arising from any reliance placed on the content. Where the content includes any translated material, BMJ does not warrant the accuracy and reliability of the translations (including but not limited to local regulations, clinical guidelines, terminology, drug names and drug dosages), and is not responsible for any error and/or omissions arising from translation and adaptation or otherwise. 
Open access This is an open access article distributed in accordance with the Creative Commons Attribution Non Commercial (CC BY-NC 4.0) license, which permits others to distribute, remix, adapt, build upon this work non-commercially, and license their derivative works on different terms, provided the original work is properly cited, appropriate credit is given, any changes made indicated, and the use is non-commercial. See: http://creativecommons.org/licenses/by-nc/4.0/.

\section{ORCID iDs}

Kyohei Shiomoto http://orcid.org/0000-0003-1741-6929

Takako Fujita http://orcid.org/0000-0002-6890-6533

Sung-A Kim http://orcid.org/0000-0002-3367-5763

\section{REFERENCES}

1 Cummings SR, Kelsey JL, Nevitt MC, et al. Epidemiology of osteoporosis and osteoporotic fractures. Epidemiol Rev 1985; 7:178-208.

2 Gullberg B, Johnell O, Kanis JA. World-wide projections for hip fracture. Osteoporos Int 1997;7:407-13.

3 Schousboe JT. Epidemiology of vertebral fractures. J Clin Densitom 2016;19:8-22.

4 Alexiou KI, Roushias A, Varitimidis SE, et al. Quality of life and psychological consequences in elderly patients after a hip fracture: a review. Clin Interv Aging 2018;13:143-50.

5 Ciubean AD, Ungur RA, Irsay L, et al. Health-related quality of life in Romanian postmenopausal women with osteoporosis and fragility fractures. Clin Interv Aging 2018;13:2465-72.

6 Svedbom A, Borgstöm F, Hernlund E, et al. Quality of life for up to 18 months after low-energy hip, vertebral, and distal forearm fractures-results from the ICUROS. Osteoporos Int 2018;29:557-66.

7 Farahmand BY, Michaëlsson K, Ahlbom A, et al. Survival after hip fracture. Osteoporos Int 2005;16:1583-90.

8 Lau E, Ong K, Kurtz S, et al. Mortality following the diagnosis of a vertebral compression fracture in the medicare population. J Bone Joint Surg Am 2008;90:1479-86.

9 Borgström F, Karlsson L, Ortsäter G, et al. Fragility fractures in Europe: burden, management and opportunities. Arch Osteoporos 2020;15:59.

10 Taguchi $Y$, Inoue $Y$, Kido $T$, et al. Treatment costs and cost drivers among osteoporotic fracture patients in Japan: a retrospective database analysis. Arch Osteoporos 2018;13:45

11 Kanis JA, Johnell O, Oden A, et al. Long-term risk of osteoporotic fracture in Malmö. Osteoporos Int 2000;11:669-74.

12 Ensrud KE. Epidemiology of fracture risk with advancing age. J Gerontol A Biol Sci Med Sci 2013;68:1236-42.

13 Kanis JA, Johnell O, Oden A, et al. FRAX and the assessment of fracture probability in men and women from the UK. Osteoporos Int 2008;19:385-97.

14 Lane NE, Epidemiology LNE. Epidemiology, etiology, and diagnosis of osteoporosis. Am J Obstet Gynecol 2006;194:S3-11.

15 De Laet C, Kanis JA, Odén A, et al. Body mass index as a predictor of fracture risk: a meta-analysis. Osteoporos Int 2005;16:1330-8.

16 Johansson $\mathrm{H}$, Kanis JA, Odén A, et al. A meta-analysis of the association of fracture risk and body mass index in women. $J$ Bone Miner Res 2014;29:223-33.

17 Kaze AD, Rosen HN, Paik JM. A meta-analysis of the association between body mass index and risk of vertebral fracture. Osteoporos Int 2018;29:31-9.

18 Fujiwara S, Kasagi F, Yamada M, et al. Risk factors for hip fracture in a Japanese cohort. J Bone Miner Res 1997;12:998-1004.

19 Rikkonen T, Sund R, Sirola J, et al. Obesity is associated with early hip fracture risk in postmenopausal women: a 25-year follow-up. Osteoporos Int 2021;32:769-77.

20 Siris ES, Miller PD, Barrett-Connor E, et al. Identification and fracture outcomes of undiagnosed low bone mineral density in postmenopausal women: results from the National osteoporosis risk assessment. JAMA 2001;286:2815-22.

21 Robbins J, Aragaki AK, Kooperberg C, et al. Factors associated with 5-year risk of hip fracture in postmenopausal women. JAMA 2007;298:2389-98.
22 Xiang B-Y, Huang W, Zhou G-Q, et al. Body mass index and the risk of low bone mass-related fractures in women compared with men: a PRISMA-compliant meta-analysis of prospective cohort studies. Medicine 2017;96:e5290.

23 Welfare. MoHLa. Japanese government report: computeradministered claims penetration rate; 2015. https://www.statista. com/statistics/255857/internet-penetration-in-japan/

24 Charlson ME, Pompei P, Ales KL, et al. A new method of classifying prognostic comorbidity in longitudinal studies: development and validation. J Chronic Dis 1987;40:373-83.

25 Sundararajan V, Henderson T, Perry C, et al. New ICD-10 version of the Charlson comorbidity index predicted in-hospital mortality. J Clin Epidemiol 2004;57:1288-94.

26 Spector TD, McCloskey EV, Doyle DV, et al. Prevalence of vertebral fracture in women and the relationship with bone density and symptoms: the chingford study. J Bone Miner Res 1993;8:817-22.

27 Kitazawa A, Kushida K, Yamazaki K, et al. Prevalence of vertebral fractures in a population-based sample in Japan. $J$ Bone Miner Metab 2001;19:115-8.

28 Yoshimura N, Kinoshita $\mathrm{H}$, Oka $\mathrm{H}$, et al. Cumulative incidence and changes in the prevalence of vertebral fractures in a rural Japanese community: a 10-year follow-up of the Miyama cohort. Arch Osteoporos 2006;1:43-9.

29 Tamaki J, Fujimori K, Ikehara S, et al. Estimates of hip fracture incidence in Japan using the National health insurance claim database in 2012-2015. Osteoporos Int 2019;30:975-83.

30 Lloyd JT, Alley DE, Hawkes WG, et al. Body mass index is positively associated with bone mineral density in US older adults. Arch Osteoporos 2014;9:175

31 Søgaard AJ, Holvik K, Omsland TK, et al. Age and sex differences in body mass index as a predictor of hip fracture: a NOREPOS study. Am J Epidemiol 2016;184:510-9.

32 Fini M, Salamanna F, Veronesi F, et al. Role of obesity, alcohol and smoking on bone health. Front Biosci 2012;4:2586-606.

$33 \mathrm{Ng} \mathrm{AC}$, Melton LJ, Atkinson EJ, et al. Relationship of adiposity to bone volumetric density and microstructure in men and women across the adult lifespan. Bone 2013;55:119-25.

34 Villareal DT, Apovian CM, Kushner RF, et al. Obesity in older adults: technical review and position statement of the American Society for nutrition and NAASO, the obesity society. Am J Clin Nutr 2005;82:923-34.

35 Felson DT, Zhang Y, Hannan MT, et al. Effects of weight and body mass index on bone mineral density in men and women: the Framingham study. J Bone Miner Res 1993;8:567-73.

36 Bouxsein ML, Szulc P, Munoz F, et al. Contribution of trochanteric soft tissues to fall force estimates, the factor of risk, and prediction of hip fracture risk. J Bone Miner Res 2007;22:825-31.

37 Premaor MO, Pilbrow L, Tonkin C, et al. Obesity and fractures in postmenopausal women. J Bone Miner Res 2010;25:292-7.

38 Compston JE, Watts NB, Chapurlat R, et al. Obesity is not protective against fracture in postmenopausal women: glow. Am J Med 2011;124:1043-50.

39 Kim SH, Yi S-W, Yi J-J, et al. Association between body mass index and the risk of hip fracture by sex and age: a prospective cohort study. J Bone Miner Res 2018;33:1603-11.

40 Holmberg $\mathrm{AH}$, Johnell $\mathrm{O}$, Nilsson PM, et al. Risk factors for fragility fracture in middle age. a prospective population-based study of 33,000 men and women. Osteoporos Int 2006;17:1065-77.

41 Amouzougan A, Lafaie L, Marotte $\mathrm{H}$, et al. High prevalence of dementia in women with osteoporosis. Joint Bone Spine 2017;84:611-4.

42 Kazama JJ. Chronic kidney disease and fragility fracture. Clin Exp Nephrol 2017;21:46-52

43 Kanis JA, Johnell O, Oden A, et al. Smoking and fracture risk: a meta-analysis. Osteoporos Int 2005;16:155-62.

44 Zhang X, Yu Z, Yu M, et al. Alcohol consumption and hip fracture risk. Osteoporos Int 2015;26:531-42.

45 Iconaru L, Moreau M, Kinnard V, et al. Does the prediction accuracy of osteoporotic fractures by BMD and clinical risk factors vary with fracture site? JBMR Plus 2019;3:e10238.

46 Gaddini GW, Turner RT, Grant KA, et al. Alcohol: a simple nutrient with complex actions on bone in the adult skeleton. Alcohol Clin Exp Res 2016;40:657-71. 